\title{
Detection of poliovirus-infected macrophages in thymus of patients with myasthenia gravis
}

\section{[}

P. Cavalcante, $\mathrm{PhD}$

M. Barberis, MD

M. Cannone, PhD

F. Baggi, PhD

C. Antozzi, MD

L. Maggi, MD

F. Cornelio, MD

M. Barbi, ScD

P. Didò, ScD

S. Berrih-Aknin, PhD

R. Mantegazza, MD

P. Bernasconi, PhD

Address correspondence and reprint requests to Dr. Pia Bernasconi, Department of Neurology IV, Neurological Institute Foundation "Carlo Besta,” Via Celoria 11, 20133 Milan, Italy

pbernasconi@istituto-besta.it

Supplemental data at www.neurology.org

\section{ABSTRACT}

Background: Genetic and environmental factors are thought to contribute to the etiology of the autoimmune disease myasthenia gravis (MG). Viral involvement has long been suspected, but direct evidence of involvement has not been found. We recently reported that Toll-like receptor 4 (TLR4) - a key activator of innate immunity - was overexpressed in the thymus of some patients with MG, suggesting that thymic infection by pathogens might be involved in MG pathogenesis. We searched for evidence of intrathymic infection in patients with MG.

Methods: Twenty-seven MG thymuses (6 involuted, 7 hyperplastic, 5 thymitis, and 9 thymoma) previously tested for TLR4 expression, 18 nonpathologic control thymuses, and 10 pathologic control thymuses from patients without MG (8 thymoma and 2 hyperplastic) were analyzed for cytomegalovirus, varicella-zoster virus, herpes simplex virus types 1 and 2, eubacteria, respiratory syncytial virus, and enteroviruses using PCR techniques. Immunohistochemistry and double immunofluorescence were used to detect enterovirus capsid protein VP1 in thymic specimens and analyze TLR4 expression in VP1-positive cells.

Results: Poliovirus was detected in 4 MG thymuses (14.8\%; 2 thymitis and 2 thymoma). No virus was detected in any control thymus. A linear correlation between plus and minus strand poliovirus RNA levels was observed in all 4 thymuses, suggesting persistent thymic infection. VP1 protein was detected in the cytoplasm of CD68-positive macrophages scattered through thymic medulla in all PV-positive thymuses. VP1 and TLR4 colocalized in infected cells.

Conclusions: Poliovirus-infected macrophages are present in thymus of some patients with myasthenia gravis, suggesting a viral contribution to the intrathymic alterations leading to the disease. Neurology ${ }^{\circledR}$ 2010;74:1118-1126

\section{GLOSSARY}

$\mathbf{A C h R}=$ acetylcholine receptor; $\mathbf{c D N A}=$ complementary DNA; CMV = cytomegalovirus; $\mathbf{E V}=$ enterovirus; $\mathbf{H C}=$ Hassall corpuscles; IgG = immunoglobulin G; $\mathbf{M G}=$ myasthenia gravis; $\mathbf{m R N A}=$ messenger RNA; PV = poliovirus; RSV = respiratory syncytial virus; $\mathbf{R T - P C R}$ = reverse-transcription PCR; TLR4 = Toll-like receptor 4; VP1 = viral protein 1.

Myasthenia gravis (MG) is an autoimmune disorder characterized by impaired neuromuscular transmission resulting in fatigability and muscle weakness. ${ }^{1}$ In $85 \%$ of cases, autoantibodies against nicotinic acetylcholine receptor at neuromuscular junction are found. ${ }^{1}$ Thymic abnormalities_-hyperplasia with germinal centers or diffuse B-cell proliferation (thymitis), or thymoma-are found in approximately $80 \%$ of patients, ${ }^{2}$ and thymectomy improves the clinical course of the disease. ${ }^{3}$ The thymus is thought to be involved in MG pathogenesis, ${ }^{1}$ but the intrathymic molecular mechanisms triggering loss of self-tolerance are unknown.

As with many autoimmune diseases, genetic and environmental factors probably influence MG development. ${ }^{4,5}$ Among environmental factors, pathogens, particularly viruses, are prime suspects, ${ }^{6-9}$ but have not previously been unequivocally demonstrated in patients with MG. ${ }^{10,11}$

From the Department of Neurology IV (P.C., F.B., C.A., L.M., F.C., R.M., P.B.), Neurological Institute Foundation "Carlo Besta," Milan, Italy; Department of Pathology (M. Barberis), Ospedale Riuniti, Bergamo, Italy; MultiLab (M.C.), Gruppo MultiMedica, Milan, Italy; Institute of Virology (M. Barbi, P.D.), University of Milan, Italy; and UMR CNRS-UPS 8162 (S.B.-A.), Centre Chirurgical Marie Lannelongue, Le Plessis Robinson, France. Study funding: Supported by the Italian Ministry of Health (P.B. and R.M.) and the Associazione Volontari Aiuti per la Sclerosi Multipla, Italy (R.M.).

Disclosure: Author disclosures are provided at the end of the article. 
We recently demonstrated that Toll-like receptor 4 (TLR4) expression is increased in MG thymitis and involuted thymus, suggesting activation of TLR4-mediated pathways. ${ }^{12}$ TLR 4 is a key component of innate immunity - the first line of defense against pathogens ${ }^{13}$ — whose activation has been associated with autoimmunity. ${ }^{14}$ TLR4 recognizes bacterial lipopolysaccharide and viral components ${ }^{15}$ as in immune response to the respiratory syncytial virus (RSV) fusion protein. ${ }^{16}$ Moreover, TLR4 transcript levels correlate with enteroviral replication in patients with cardiomyopathy, ${ }^{17}$ whereas coxsackievirus infection up-regulates TLR4 on mast cells and macrophages, resulting in progression to chronic autoimmune heart disease in susceptible mice. ${ }^{18}$

We wondered whether TLR4 overexpression in MG thymus ${ }^{12}$ was indicative of intrathymic virus infection and, in the present study, report results of our search for evidence of viral infection in thymuses previously studied for TLR 4 expression.

METHODS Patients and thymuses. We studied 27 MG thymuses ( 6 involuted, 7 follicular hyperplastic, 5 thymitis, and 9 thymoma), all but 1 previously analyzed for TLR 4 expression and followed at our institute since 2004. ${ }^{12}$ Patients' clinical characteristics are shown in table 1 . We also examined 18 nonpathologic thymuses obtained during heart surgery in patients with cardiopathy (mean age 23.6 years, SD 15 , range $4-56$ ) and 10 pathologic thymuses ( 8 thymoma and 2 hyperplastic thymuses)

\begin{tabular}{|c|c|c|c|c|}
\hline \multicolumn{5}{|c|}{ Table 1 Clinical features of patients with myasthenia gravis } \\
\hline Thymus histology & $\begin{array}{l}\text { Involuted } \\
(n=6)\end{array}$ & $\begin{array}{l}\text { Hyperplasia } \\
(n=7)\end{array}$ & $\begin{array}{l}\text { Thymitis } \\
(\mathrm{n}=5)\end{array}$ & $\begin{array}{l}\text { Thymoma } \\
(\mathrm{n}=9)\end{array}$ \\
\hline Sex, F/M & $3 / 3$ & $6 / 1$ & $3 / 2$ & $6 / 3$ \\
\hline Age at disease onset, mean $\pm S D, y$ & $27.9 \pm 8.3$ & $22.2 \pm 3.8$ & $32.6 \pm 3.6$ & $46.8 \pm 20.1$ \\
\hline Disease onset, $<40 \mathrm{y} />40 \mathrm{y}$ & $6 / 0$ & $7 / 0$ & $5 / 0$ & $4 / 5$ \\
\hline Age at surgery, mean $\pm S D, y$ & $31.6 \pm 8.6$ & $24.2 \pm 4.8$ & $34.4 \pm 4.3$ & $47.8 \pm 20.1$ \\
\hline Ab AChR positive & 5 & 5 & 3 & 9 \\
\hline Ab AChR/MuSK negative & 1 & 2 & 2 & 0 \\
\hline \multicolumn{5}{|l|}{ Maximum disease severity (nadir) ${ }^{\mathrm{a}}$} \\
\hline 1 & $\mathrm{n}=0$ & $\mathrm{n}=1$ & $\mathrm{n}=0$ & $\mathrm{n}=0$ \\
\hline IIA & $\mathrm{n}=1$ & $n=3$ & $\mathrm{n}=2$ & $\mathrm{n}=0$ \\
\hline IIB & $\mathrm{n}=3$ & $n=3$ & $\mathrm{n}=4$ & $n=7$ \\
\hline III & $\mathrm{n}=2$ & $\mathrm{n}=0$ & $\mathrm{n}=0$ & $n=2$ \\
\hline Immunosuppressive therapy & $6 / 6$ & $3 / 7$ & $3 / 5$ & $7 / 9$ \\
\hline
\end{tabular}

Abbreviations: $\mathrm{Ab}=$ antibody; $\mathrm{AChR}=$ acetylcholine receptor; $\mathrm{MuSK}=$ muscle-specific kinase.

${ }^{\text {aD }}$ Disease severity was graded according to Osserman classification. ${ }^{39}$ from patients without MG (mean age 50.4 years, SD 15, range 24-76).

For immunohistochemistry, fresh thymic fragments were frozen in isopentane at $-55^{\circ} \mathrm{C}$ with OCT and stored at $-80^{\circ} \mathrm{C}$; for DNA and RNA extraction, fragments were snap frozen without OCT and stored in RNAlater (Ambion, Foster City, CA) at $-80^{\circ} \mathrm{C}$

Standard protocol approvals, registrations, and patient consents. The study was approved by the Ethics Committee of the Carlo Besta Neurological Institute, and each patient provided written informed consent for thymectomy and use of the thymus for research.

Detection of DNA viruses. DNA was extracted using the standard phenol-chloroform method. Primers for cytomegalovirus (CMV), varicella-zoster virus, herpes simplex types 1 and 2, and eubacteria were selected from published sequences, and PCR reactions were performed as described. ${ }^{19-21}$ For details, see appendix e-1 on the Neurology ${ }^{\circledR}$ Web site at www.neurology.org.

Detection of human respiratory syncytial virus RNA. The NucliSens miniMAG extraction system with NucliSens magnetic extraction reagents (bioMerieux, Marcy l'Etoile, France) were used for RNA extraction. For RSV A + B RNA amplification and detection, the NucliSens EasyQ RSV A+B Real-Time NASBA assay was used in conjunction with the $\mathrm{Nu}$ cliSens EasyQ Basic Kit Amplification Reagents, NucliSens EasyQ Analyzer, and NucliSens EasyQ Director software (for details, see appendix e-1).

Detection of enterovirus RNA. Total RNA was extracted from 20 to $100 \mathrm{mg}$ of frozen thymus using TRIzol (Invitrogen Life Technologies, Carlsbad, CA) and treated with DNase I (Ambion). Random-primed complementary DNA (cDNA) was prepared using Superscript II reverse transcriptase (Invitrogen) following the manufacturer's instructions.

cDNA corresponding to $500 \mathrm{ng}$ total RNA was subjected to nested PCR using primers, designed by Primer Express software (Applied Biosystems), specific for the 5' untranslated conserved region (5'-UTR; GenBank accession number DQ133458): EVout forward 5'-CGGTACCTTTGTACGCCTGTT-3' and EV-out reverse 5'-GGACACCCAAAGTAGTCGGTT-3'; EVinn forward $5^{\prime}$-TCAAGCACTTCTGTTTCCC- $3^{\prime}$ and EV-inn reverse 5'-AGACTCTTCGCACCATGTC-3'.

PCR reactions were performed in $50 \mu \mathrm{L}$ containing $1 \times \mathrm{PCR}$ buffer, $1.5 \mathrm{mM} \mathrm{MgCl}, 0.2 \mathrm{mM}$ deoxyribonucleotide triphosphates, $1 \mathrm{U}$ of DNAZyme (Finnzyme, Espoo, Finland), and 0.1 $\mu \mathrm{M}$ of each EV-out primer (first PCR) or $0.3 \mu \mathrm{M}$ of each EV-inn primer (second PCR). First and second PCRs consisted of 25 (first) or 35 (second) cycles, at $94^{\circ} \mathrm{C}$ for $30 \mathrm{~s}, 56^{\circ} \mathrm{C}$ (first) or $52^{\circ} \mathrm{C}$ (second) for $30 \mathrm{~s}$, and $72^{\circ} \mathrm{C}$ for $30 \mathrm{~s}$, followed by extension for 7 minutes at $72^{\circ} \mathrm{C}$. As a positive control, we used a plasmid containing the $5^{\prime}-$ UTR region of the EV genome (Nanogen, San Diego, CA). Carryover contamination by the amplified product was avoided by physical separation of first and second amplifications and frequent surface decontamination with ultraviolet light. As a control of RNA integrity and retrotranscription efficiency, the $\beta$-actin gene was amplified (appendix e-1).

EV PCR products were cloned using the TOPO TA Cloning system (Invitrogen), and at least 5 bacterial colonies from each EVpositive patient were sequenced using ABI 3100 Genetic Analyzer (Applied Biosystems). Sequences were analyzed with SeqScape software version 2.1.1 (Applied Biosystems) and aligned with 
GenBank, DDBJ, and EMBL database sequences using the Blastn 2.2.21 algorithm (http://blast.ncbi.nlm.nih.gov/Blast.cgi).

Analysis of poliovirus RNA polarity. Sequencing showed the EV PCR products to be poliovirus (PV). To determine PV RNA polarity, total RNA from thymuses was retrotranscribed using EV-out reverse and forward primers, separately, as described ${ }^{17}$ with modifications (appendix e-1). cDNA of plus and minus strand PV RNA was PCR amplified with EV-inn primers using the above-described conditions. To assess plus and minus strand RNA levels, we tested 29, 32, 35, 38, and 41 amplification cycles and chose 35 cycles at which both strands were amplified exponentially. For each patient, PCR product band densities were calculated using Quantity One software (BioRad Laboratories, Hercules, CA) and normalized to that of $\beta$-actin. cDNA was synthesized and PCR amplified in 4 independent experiments.

Immunohistochemistry. EV viral protein 1 (VP1) was detected in thymuses using mouse monoclonal $\mathrm{EV}$-specific antibody (1:1,000; clone 5-D8/1; Dako, Glostrup, Denmark ${ }^{22,23}$ and the EnVision ${ }^{+}$polymer technique (Dako). For antigen retrieval, rehydrated sections underwent least two 7-minute cycles in a microwave oven in ethylenediaminetetraacetic acid buffer ( $\mathrm{pH}$ 9.0). Immunostaining was conducted in a Dako Autostainer Plus. Diaminobenzidine was used as a chromogen, and Mayer hematoxylin was used as a nuclear stain.

To identify VP1-positive cell phenotypes, anti-VP1 staining was performed in combination with mouse monoclonal pan anticytokeratin (1:50, clone AE1/AE3; Zymed Laboratories, South San Francisco, CA) or mouse monoclonal antiCD68 (1:100, clone KP-1; Dako). VP1 was visualized with fast red; cytokeratin or CD68 positivity was visualized with diaminobenzidine. Immunohistochemistry specificity was checked by omitting primary antibodies or replacing them with irrelevant antiserum.

VP1/CD68 double-positive cells were counted on 10 adjacent areas per section (total area $3.12 \mathrm{~mm}^{2}$ as viewed in a wideangle Leitz Diaplan microscope [Leica, Milan, Italy] with $\times 10$ eyepiece and $\times 40$ objective).

Double immunofluorescence. Double immunofluorescence stainings were performed with rabbit polyclonal antiTLR4 antibody (1:20; Santa Cruz Biotechnology, Santa Cruz, CA) in combination with either mouse monoclonal anti-VP1 (Dako) or mouse monoclonal anti-CD68 (Dako) antibodies. Frozen $6-\mu \mathrm{m}$ sections were fixed in $4 \%$ paraformaldehyde for $10 \mathrm{~min}$ utes and treated with $20 \mu \mathrm{g} / \mathrm{mL}$ proteinase $\mathrm{K}$ for 10 minutes. Aspecific binding was blocked with phosphate-buffered saline plus $10 \%$ animal serum (Dako) for 1 hour (all at room temperature). Sections were incubated overnight at $4^{\circ} \mathrm{C}$ with primary antibodies followed by 1-hour incubation at room temperature with $\mathrm{Cy} 2-$ conjugated goat anti-mouse immunoglobulin G ( $\operatorname{IgG}$ ) and Cy3conjugated goat anti-rabbit IgG (Jackson Immunoresearch Laboratories, West Grove, PA). Images were viewed in a confocal laser-scanning microscope (EclipseE600; Nikon, Sesto Fiorentino, Italy) and analyzed using LaserSharp 2000 software (Bio-Rad). Single- and double-positive cells were counted on 4 adjacent field areas per section at $\times 40$ magnification.

Detection of poliovirus antibody. Neutralizing serum antibodies in the 27 patients with MG were titrated on Vero cells in microtiter plates. The antibody titer was the highest serum dilution that protected $50 \%$ of cultures against 100 tissue culture infective doses (TCID50) of the 3 Sabin strains. Titers (dilutions) of $1: 8$ were considered protective..$^{24}$

Statistical analysis. The relationship between plus and minus PV RNA levels was examined by using the Pearson productmoment correlation coefficient $\left(R^{2}\right)$. Analysis was performed by using Origin 6.0 software (OriginLab Corporation, Northampton, MA). The $\chi^{2}$ test was used to test the hypothesis that MG and non-MG groups differed in relation to viral presence.

RESULTS Poliovirus RNA detection. Most thymuses were negative for all viruses tested. However, by nested reverse-transcription PCR (RT-PCR), 4 of 27 MG thymuses (14.8\%; 2 thymitis and 2 thymoma) were positive for EV RNA (figure 1A). EV RNA was not detected in any of the 28 control thymuses (figure 1A). Absence of PV in nonpathologic and pathologic non-MG thymuses suggests a relationship between PV and MG ( $p=0.042, \chi^{2}$ test).

Sequence analysis of the PCR products from the positive thymus samples showed $98 \%$ identity with the sequence of PV type 1 (GenBank Accession No. AY928387.1) ${ }^{25}$ (figure e-1). Using the same PCRbased procedures, PV RNA was not detected in the serum of any patient with MG.

PV is a positive-sensed single-stranded RNA virus. During replication, the plus strand is transcribed to the minus strand, which is the template for plus strand genomes forming new virions. ${ }^{26}$ By RT-PCR, plus and minus strand PV RNAs were present in all 4 PV-positive samples (figure 1B) at levels that correlated directly with each other $\left(R^{2}=0.96, p=0.02\right.$; figure $1 C$ ), suggesting persistent $\mathrm{PV}$ infection.

Localization of enterovirus capsid protein. By immunohistochemistry, the VP1 capsid protein was present in all 4 PV RNA-positive thymuses and was located in the cytoplasm of CD68-positive cells having macrophage morphology (figure 2). In the 2 thymitis specimens, VP1-positive CD68-positive cells ( 2 to 8 positive cells per high power field) were concentrated in the medulla, frequently around the Hassall corpuscles (HC) (figure 2, A and B). VP1 positivity was also present in some cells of epithelial morphology in the external HC layer (figure 2A). Epithelial cells outside the HC were never VP1 positive. In the 2 thymoma cases, VP1-positive CD68positive cells (1 to 3 positive cells per high power field) were scattered within neoplastic tissue (figure 2, C and D). In none of the thymuses negative for PV RNA (MG and control) was VP1 positivity ever found.

CD68, VP1, and TLR4 colocalization. TLR4 expression on macrophages in PV-positive and PV-negative thymuses was explored. In all PV-positive specimens, some CD68-positive macrophages expressed TLR4 (figure 3). Percentages of TLR4-positive macro- 
Figure 1 Poliovirus RNA detected in myasthenia gravis thymus specimens
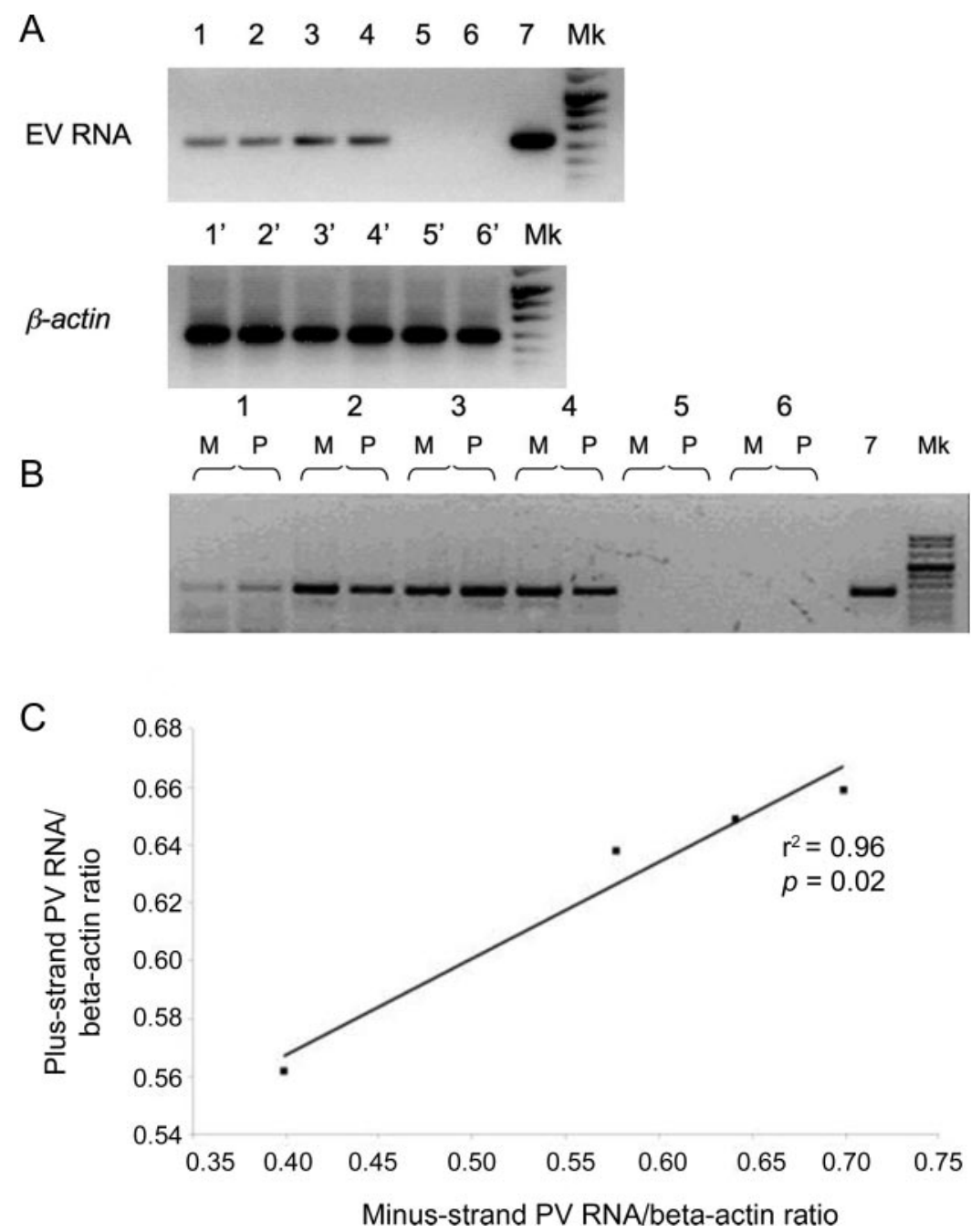

(A) Total RNA extracted from thymus fragments of patients with myasthenia gravis (MG) (lanes 1 through 5) and controls (lane 6), analyzed by nested reverse-transcription PCR for the presence of enterovirus (EV) RNA. Lanes 1 through 4 show EV-positive MG thymuses, lane 5 is EV-negative MG, lane 6 is normal thymus, and lane 7 shows PCR of plasmid containing cloned conserved region of the $5^{\prime}$-UTR of the EV genome (positive control). $\beta$-Actin (lanes $1^{\prime}$ through $6^{\prime}$ ) served as internal control for complementary DNA integrity. (B) Gel electrophoresis of 265-bp amplification products of minus $(M)$ and plus $(P)$ strand poliovirus (PV) RNAs from MG (paired lanes 1 through 5) and normal (paired lane 6) thymuses. The figure shows the result of 1 experiment; the 3 other replications produced similar results. Lane 7 shows PCR of positive control. Mk = DNA molecular weight marker (size range 191,114 bp), mixture of pUCBM21 DNA, cleaved with Hpall, and pUCBM21 DNA, cleaved with Dral and HindIII. (C) Correlation plot between minus and plus strand PV RNA levels, normalized to $\beta$-actin, quantified in the thymus of patients with MG. Minus and plus strand PV RNA levels correlated directly with each other in each of the 4 PV-positive thymuses $\left(R^{2}=0.96, p=0.02\right)$.

phages were similar in the PV-positive thymoma and thymitis thymuses (figure 3, C and F; and table e-1) and higher in the PV-negative MG and control thymuses (figure 3 and table e-1). The expression of TLR4 on PV-infected macrophages was explored next. Double immunofluorescence for VP1 and TLR4 showed that, in all 4 VP1-positive thymuses, cells positive for VP1 were often positive for TLR4 (figure 4). In the thymomas, only rare scattered cells expressed TLR4 (mean 15 cells per high power field), and $30.6 \%$ of these expressed VP1 (figure 4, A-C). In thymitis specimens, TLR4-positive cells were common (mean 67.5 cells per high power field), and although only a few of these expressed VP1, VP1positive cells always expressed TLR4 (figure 4, D-H); VP1-TLR4 double-positive cells were disseminated throughout the medulla (figure 4, F-H) and were often present around HC (figure 4F) (mean 2.5 double-positive cells per high power field, 3.7\% of TLR4-positive cells).

In MG and control thymuses negative for PV RNA, VP1 positivity was never found (figure 4, I$\mathrm{K})$, although the thymitis cases expressed TLR 4 abundantly (figure 4J).

Neutralizing antibody. Most patients (25 of 27) had neutralizing antibodies to all the 3 types of PV in serum (titers $>1: 8$ ). Serologic results are summarized in table e-2. Previously collected serologic data from a control group of 103 healthy subjects known to be unvaccinated $^{27}$ and from a control group of 1,007 healthy subjects known to be vaccinated (personal data) are also shown in table e-2. All 4 PV-positive (thymus) patients were seropositive (range 1:8 to 1:64 against type $1,1: 32$ to $1: 128$ against type 2 , and $1: 8$ to $>1: 2,048$ against type 3 ). These positivities were similar to those observed in the other patients except for the uniquely high titer of $>1: 2,048$ against type 3 poliovirus in a PV-positive patient with thymoma.

DISCUSSION We previously showed that TLR4 - a key molecule in innate immunity—was up-regulated in the thymuses of some patients with $M G,{ }^{12}$ suggesting that intrathymic infection might switch the immune system from a protective response to a harmful autoimmune response. We looked for signs of TLR4-associated infection in the thymuses of the patients with MG and, in the present study, report that 4 of 27 MG thymuses (2 thymitis and 2 thymoma) were positive for PV RNA and VP1 capsid protein. The 2 thymitis thymuses expressed high levels of TLR4 messenger RNA (mRNA), whereas the 2 thymoma thymuses expressed TLR 4 mRNA at a level comparable to that of normal thymuses. ${ }^{12}$ The absence of viral RNA in the serum of all 27 patients with MG suggested the absence of acute PV infection. Unfortunately, peripheral blood mononuclear cells from the $4 \mathrm{PV}$-positive patients were unavailable, and the possibility that PV-infected thymus cells could be due to migration of circulating infected macrophages could not be assessed.

PV is a positive-stranded RNA EV of the Picornaviridae family, causing acute infections in humans ${ }^{28}$; 

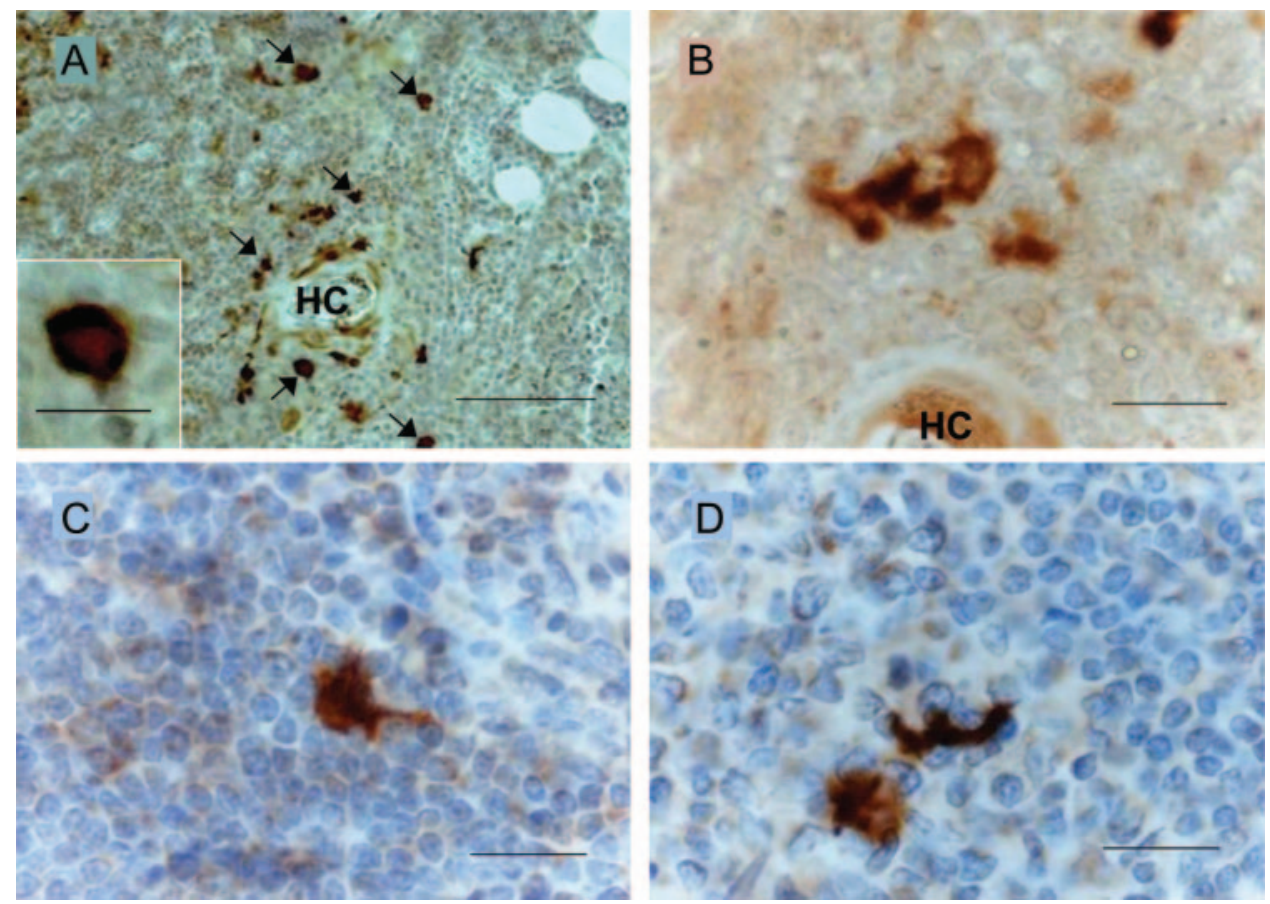

(A and B) Double immunostaining for capsid protein VP1 (red) and CD68 (brown) in both thymitis specimens positive for poliovirus RNA, reveals the presence, in thymic medulla, of CD68-positive cells (macrophages) with VP1 in the cytoplasm (arrows and inset in A). Double-positive cells were preferentially localized around the Hassall corpuscles (HC). (C and D) VP1-positive/CD68-positive macrophages in each of the thymoma cases positive for poliovirus RNA. Tissue sections counterstained with hematoxylin. Bars: $100 \mu \mathrm{m}$ in $A ; 20 \mu \mathrm{m}$ in B-D; $15 \mu \mathrm{m}$ in inset in A.

if the virus enters the CNS, it causes poliomyelitis, although this occurs in $<1 \%$ of natural infections with wild-type PV.28 PV is usually cleared from the body, but some picornaviruses can persist in host tissues, sometimes for years after the initial infection. ${ }^{29}$ Persistent EV RNA has been found in patients with neuropathic and muscular diseases, including postpolio syndrome ${ }^{30}$ and dilated cardiomyopathy. ${ }^{17} \mathrm{Vi}-$ ral persistence is characterized by synthesis of similar quantities of plus and minus RNA strands, which form relatively stable double-stranded RNA necessary for viral latency. ${ }^{26}$ Plus and minus PV RNA strands were present at comparable levels in our PVpositive cases (figure 1, B and C), suggesting persistent PV infection in their thymus.

Positive strand EV RNA is translated into nonstructural and structural proteins, including VP1.28 VP1 was found in all PV RNA-positive thymus specimens (figures 2 and 4), indicating that viral protein was synthesized, and colocalized with macrophages. This finding is not unusual because differentiated macrophages and dendritic cells express the PV receptor (CD155), can be productively infected with $\mathrm{PV}$, and may also retain PV receptor expression. ${ }^{31}$ Immunocompetent SWR/J mice inoculated intraperitoneally with the EV coxsackievirus B3 develop chronic heart muscle infection, characterized by per- sistent infection mainly localized in B cells and macrophages. ${ }^{32}$ Viral replication in a small fraction of brain macrophages was reported after infection with Theiler virus, a picornavirus responsible for persistent demyelinating CNS infection in mice. ${ }^{32}$ Similarly, in PV-positive patients, thymic macrophages could be a supplementary reservoir of viral genome, which might contribute to the creation or maintenance of a chronically inflamed thymic microenvironment, and thus act as an adjuvant in priming the autoimmune process.

We found that in all $4 \mathrm{PV}$-positive thymuses, VP1-positive cells expressed TLR4 (figure 4). In thymoma, $30.6 \%$ of the TLR4-positive cells were VP1 positive, whereas in thymitis, VP1-positive cells always expressed TLR4. TLR4 expression was low (figures 3 and 4) in thymoma and present mainly on macrophages (figure 3C). TLR4 expression was greater in the thymitis due to expression of TLR4 also by a high number of epithelial cells (reference 12 and figures 3 and 4). Although the relationship between intrathymic VP1 presence and TLR4 expression in thymus remains to be clarified, our findings suggest that a persistent viral infection would generate a "danger signal" leading to the creation of an inflamed thymic microenvironment favoring initiation or perpetuation of the autoimmune response. 
Figure 3 CD68-positive macrophages express TLR4 in poliovirus-positive thymoma and thymitis myasthenia gravis thymuses
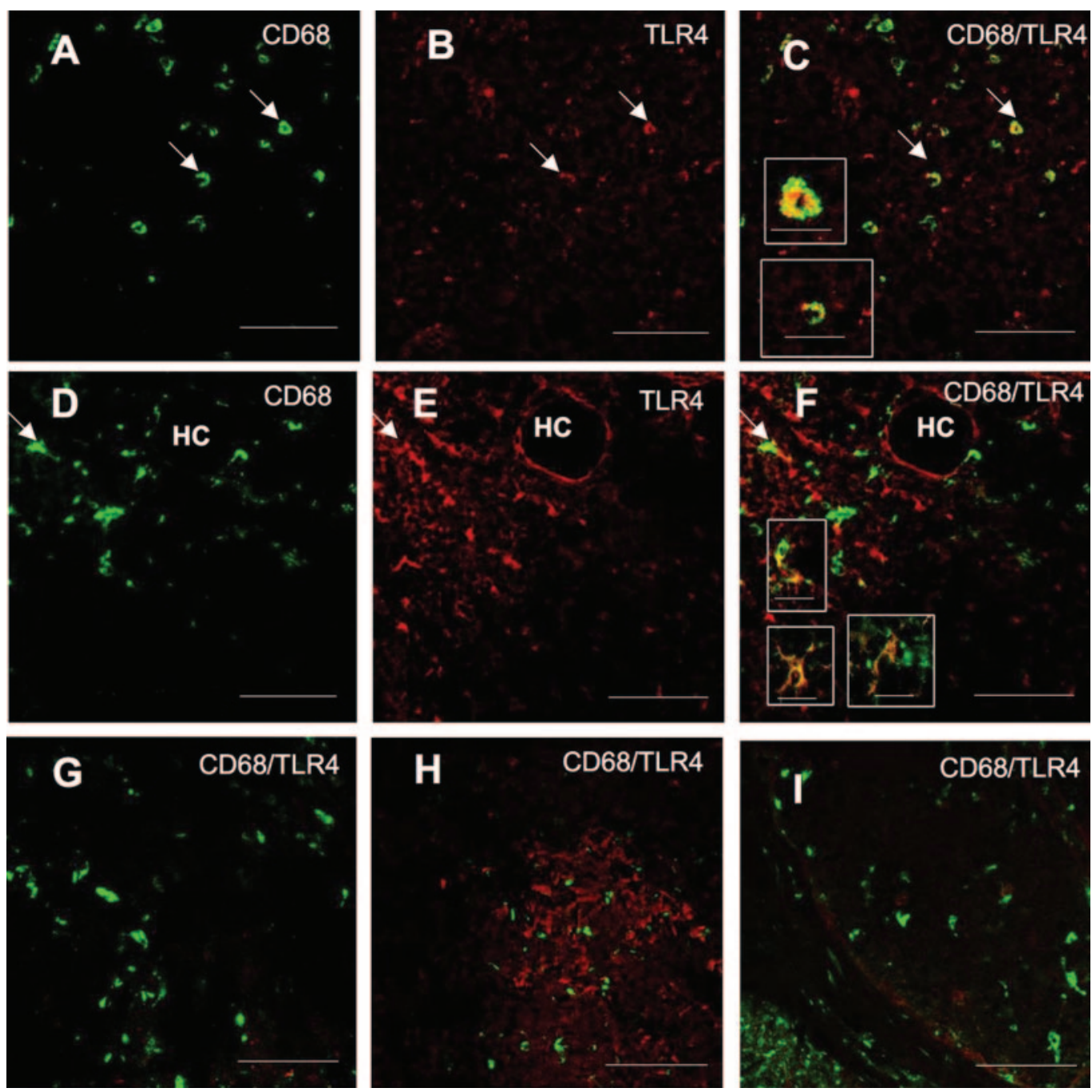

(A-C) In poliovirus (PV)-positive thymoma, some macrophages (green) (arrows) express Toll-like receptor 4 (TLR4) (red) on their surfaces (see also the 2 insets in C). (D-F) In PV-positive thymitis, most cells are TLR4 positive; some are macrophages (arrow in D-F) present near the Hassall corpuscles $(\mathrm{HC})$ or diffuse in thymic medulla (insets in F). In PV-negative thymoma (G) and thymitis thymuses $(\mathrm{H})$, and also in normal thymus (I), CD68-positive macrophages expressing TLR4 were rare or absent. Bars: $50 \mu \mathrm{m}$ in A-l; $15 \mu \mathrm{m}$ in insets in C; $10 \mu \mathrm{m}$ in insets in F.

To our knowledge, PV has not previously been documented in human pathologic thymus, although CMV, HIV-1, coxsackievirus, and other viruses can infect human thymic epithelium. ${ }^{33,34} \mathrm{MG}$ cases with human T-lymphotropic virus type I infection of the thymus have also been reported, ${ }^{7}$ and MG has been documented immediately after viral infection. ${ }^{8} \mathrm{Al}$ though only $14.8 \%$ of our MG thymuses were PV positive, and none of the other investigated viruses were detected, our finding suggests that local infection may participate in the chronic inflammation characteristic of MG. In such cases, thymectomy might be effective because it removes virus-infected cells. Another possibility is that the virus has "hit and run," 5 the autoimmune process becoming apparent after the virus has been cleared from the body.
The 2 PV-positive patients with thymoma were positive for acetylcholine receptor (AChR)-specific antibodies, whereas the patients with thymitis were seronegative (table e-3). Some seronegative patients have recently been shown to have low-affinity antiAChR antibodies, ${ }^{35}$ and we cannot exclude this possibility for our seronegative patients.

One of the $4 \mathrm{PV}$-positive patients (a patient with thymoma) received only acetylcholinesterase inhibitors before thymectomy (table e-3), and we can exclude, for this patient, an effect of immunosuppression on the PV infection. The other 3 patients received immunosuppression, which could have amplified previously established thymic infection and inflammation.

Twenty-five of our 27 patients had protective immunity against all 3 PV types (table e-2), but infor- 

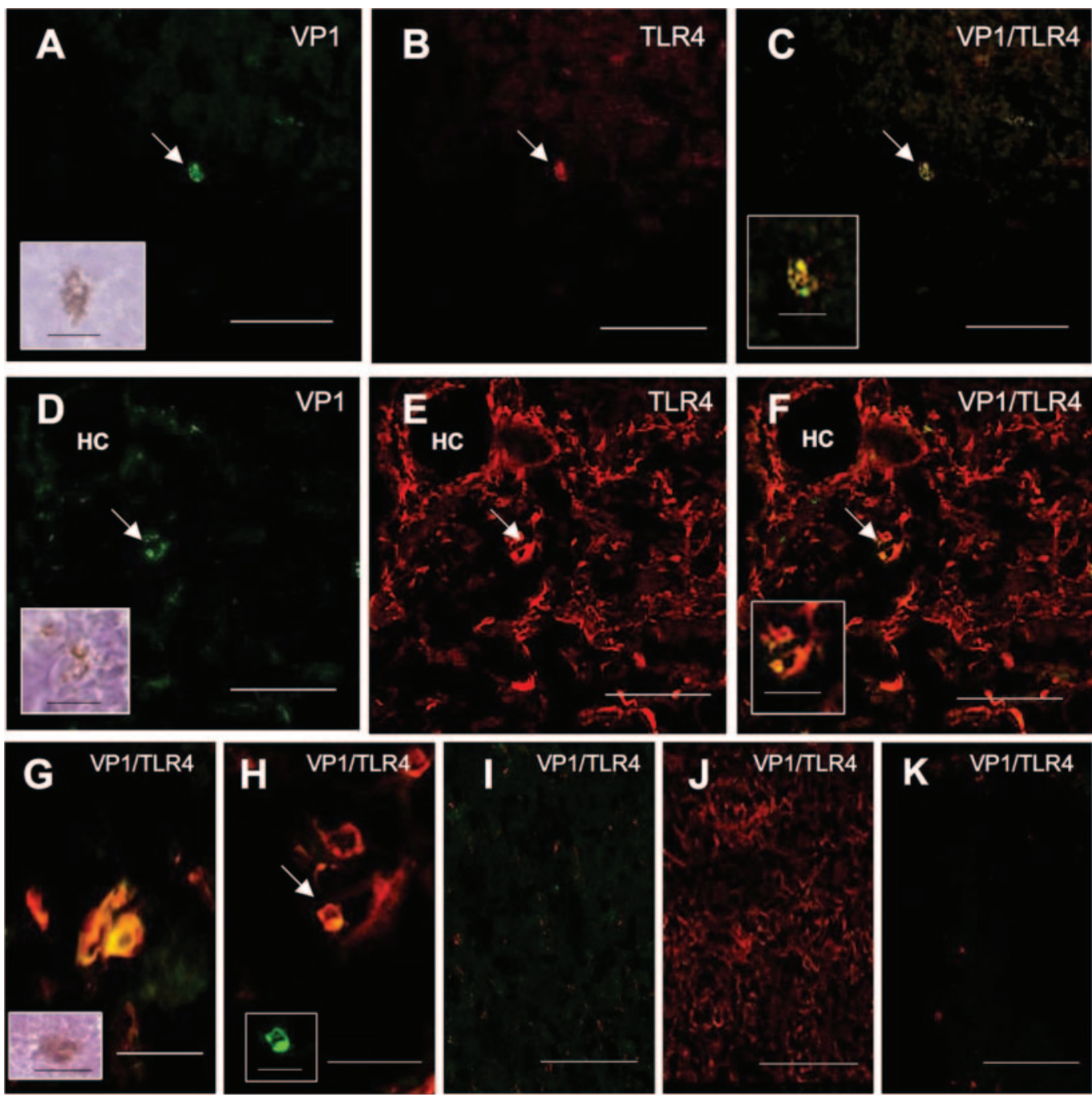

In thymoma thymuses (A-C), few cells are positive. (A) Viral protein 1 (VP1)-positive cell (green) that is also Toll-like receptor 4 (TLR4) positive: red in B and yellow in C. In thymitis thymuses (D-H), many TLR4-expressing cells are present in the medulla, especially around the Hassall corpuscles (HC) (E). VP1-positive cells (D; green, arrow) are positive for TLR4 (E; red, arrow and $F$; yellow, arrow). The higher magnifications in $\mathrm{G}$ and $\mathrm{H}$ show double positivity (yellow) for VP1 and TLR4. In RNA poliovirus-negative thymoma (I), thymitis $(\mathrm{J})$, and control thymuses $(\mathrm{K})$, no VP1-positive cells were observed, although TLR4positive cells were present (less in thymoma [I] and normal thymus [K] than thymitis [J]). The insets in A, D, and G show VP1-positive cells detected by single staining in sections adjacent to those shown in the respective main panels. The insets in $\mathrm{C}$ and $\mathrm{F}$ are enlargements of the VP1/TLR4 double-positive cells shown in the main panels. The inset in $\mathrm{H}$ shows the same cell as in the main panel (arrow, VP1 and TLR4 positive) selected to reveal only VP1 positivity (cell in medulla). Bars: $50 \mu \mathrm{m}$ in $\mathrm{A}-\mathrm{F}$ and $\mathrm{I}-\mathrm{K} ; 20 \mu \mathrm{m}$ in $\mathrm{G}$ and $\mathrm{H} ; 15 \mu \mathrm{m}$ in insets in $\mathrm{A}, \mathrm{C}, \mathrm{D}$, and $\mathrm{F}-\mathrm{H}$.

mation about polio vaccination was not available. Because PV vaccination has been available in Italy since 1958 and became compulsory in 1966, PV seropositivity was likely due to vaccination in patients born after 1960 (MG2 group in table e-2) and to vaccination as adults or direct contact with the virus in the patients with MG who were born before 1960 (MG1 group in table e-2). A control group (control group in table e-2) of healthy subjects born before 1960 and known to be unvaccinated ${ }^{27}$ had protective immunity against at least 1 of the 3 PV types (table e-2). The 2 PV-positive thymoma cases were born before 1960; the 2 PV-positive thymitis cases were born after 1960 . Whether these patients were vaccinated or not, it is unclear how virus could persist in the thymus in the presence of neutralizing antibodies. PV persistence is not unusual in individuals with humoral immunodeficiency, ${ }^{36}$ but whether this occurs also in patients with MG is not known. It is noteworthy that vaccine strains of $\mathrm{PV}$ persist in some vaccinated individuals and that polio outbreaks may be due to vaccine-derived PV. ${ }^{37,38}$ However, irrespective of whether the PV infection observed in MG thymuses occurred as a consequence of direct contact 
of the patients with wild-type virus or was derived from vaccine, our findings provide new evidence for a possible viral contribution to MG.

\section{AUTHOR CONTRIBUTIONS}

Statistical analysis was conducted by Dr. F. Baggi.

\section{ACKNOWLEDGMENT}

The authors thank Don Ward for critical discussion and help with the English; Drs. Lorenzo Novellino and Luisella Spinelli for performing the thymectomies at the Ospedale Riuniti, Bergamo, Italy; and all physicians of the Neurology IV Unit at the Besta Neurological Institute of Milan for referring the patients.

\section{DISCLOSURE}

Dr. Cavalcante, Dr. Barberis, Dr. Cannone, and Dr. Baggi report no disclosures. Dr. Antozzi serves on the editorial board of Neurological Sciences. Dr. Maggi, Dr. Cornelio, Ms. Barbi, Ms. Didò, and Dr. BerrihAknin report no disclosures. Dr. Mantegazza has received funding for Congress attendances from Merck Serono and sanofi-aventis. Dr. Bernasconi reports no disclosures.

Received July 30, 2009. Accepted in final form January 27, 2010.

\section{REFERENCES}

1. Vincent A. Unravelling the pathogenesis of myasthenia gravis. Nat Rev Immunol 2002;2:797-804.

2. Marx A, Wilisch A, Schultz A, Gattenlohner S, Nenninger R, Müller-Hermelink HK. Pathogenesis of myasthenia gravis. Virchows Arch 1997;430:355-364.

3. Mantegazza R, Baggi F, Bernasconi P, et al. Video-assisted thoracoscopic extended thymectomy and extended transsternal thymectomy ( $\mathrm{T}-3 \mathrm{~b})$ in non-thymomatous myasthenia gravis patients: remission after 6 years of follow-up. J Neurol Sci 2003;212:31-36.

4. Gregersen PK, Behrens TW. Genetics of autoimmune diseases: disorders of immune homeostasis. Nat Rev Genet 2006;7:917-928.

5. Munz C, Lunemann JD, Teague Getts M, Miller SD. Antiviral immune response: triggers or triggered by autoimmunity? Nat Rev Immunol 2009;9:246-258.

6. Schwimmbeck PL, Dyrberg T, Drachman DB, Oldstone MBA. Molecular mimicry and myasthenia gravis: an autoantigenic site of the acetylcholine receptor $\alpha$-subunit that has biological activity and reacts immunochemically with herpes simplex virus. J Clin Invest 1989;84:1174-1180.

7. Manca N, Perandin F, De Simone N, Giannini F, Bonifati D, Angelini C. Detection of HTLV-I tax-rex and pol gene sequences of thymus gland in large group of patients with myasthenia gravis. J Acquir Immune Defic Syndr 2002;29: 300-306.

8. Korn IL, Abramsky O. Myasthenia gravis following viral infection. Eur Neurol 1981;20:435-439.

9. Stefansson K, Dieperink ME, Richman DP, Gomez CM, Marton LS. Sharing of antigenic determinants between the nicotinic acetylcholine receptor and proteins in Escherichia coli, Proteus vulgaris, and Klebsiella pneumoniae: possible role in the pathogenesis of myasthenia gravis. N Engl J Med 1985;312:221-225.

10. Tindall RS, Cloud R, Lucky L, Rosenberg RN. Serum antibodies to cytomegalovirus in myasthenia gravis: effects of thymectomy and steroids. Neurology 1978;28:273-277.
11. Klavinskis LS, Willcox N, Oxford JS, Newsom-Davis J. Antivirus antibodies in myasthenia gravis. Neurology 1985;35:1381-1384.

12. Bernasconi P, Barberis M, Baggi F, et al. Increased Tolllike receptor 4 expression in thymus of myasthenic patients with thymitis and thymic involution. Am J Pathol 2005; 167:129-139.

13. Uematsu $S$, Akira S. Toll-like receptors and innate immunity. J Mol Med 2006;84:712-725.

14. Marsland BJ, Kopf M. Toll-like receptors: paving the path to $\mathrm{T}$ cell-driven autoimmunity? Curr Opin Immunol 2007;19:611-614.

15. Barton GM. Viral recognition by Toll-like receptors. Semin Immunol 2007;19:33-40.

16. Kurt-Jones EA, Popova L, Kwinn L, et al. Pattern recognition receptors TLR4 and CD14 mediate response to respiratory syncytial virus. Nat Immunol 2000;1:398-401.

17. Satoh M, Nakamura M, Akatsu T, Shimoda Y, Segawa I, Hiramori K. Toll-like receptor 4 is expressed with enteroviral replication in myocardium from patients with dilated cardiomyopathy. Lab Invest 2004;84:173-181.

18. Fairweather D, Frisancho-Kiss S, Rose NR. Viruses as adjuvants for autoimmunity: evidence from Coxsackievirusinduced myocarditis. Rev Med Virol 2005;15:17-27.

19. Markoulatos P, Georgopoulou A, Siafakas N, Plakokefalos E, Tzanakaki G, Kourea-Kremastinou J. Laboratory diagnosis of common herpesvirus infections of the central nervous system by a multiplex PCR assay. J Clin Microbiol 2001;39:4426-4432.

20. Saito D, Leonardo Rde T, Rodrigues JL, Tsai SM, Höfling JF, Gonçalves RB. Identification of bacteria in endodontic infections by sequence analysis of $16 \mathrm{~S}$ rDNA clone libraries. J Med Microbiol 2006;55:101-107.

21. Marshall DS, Linfert DR, McCarter YS, Tsongalis GJ. Identification of herpes simplex virus genital infection: comparison of a multiplex PCR assay and traditional viral isolation techniques. Mod Pathol 2001;14:152-156.

22. Foulis AK, Farquharson MA, Cameron SO, McGill M, Schönke H, Kandolf R. A search for the presence of the enteroviral capsid protein VP1 in pancreases of patients with type 1 (insulin-dependent) diabetes and pancreases and hearts of infants who died of coxsackieviral myocarditis. Diabetologia 1990;33:290-298.

23. Bourlet T, Gharbi J, Omar S, Aouni M, Pozzetto B. Comparison of a rapid culture method combining an immunoperoxidase test and a group specific anti-VP1 monoclonal antibody with conventional virus isolation techniques for routine detection of enteroviruses in stools. J Med Virol 1998;54:204209.

24. World Health Organization. Guidelines for WHO/EPI Collaborative Studies on Poliomyelitis. Standard Procedure for Determining Immunity to Poliovirus Using the Microneutralization Test. WHO/EPI/GEN/93.9. Geneva: World Health Organization; 1993.

25. Chen-Fu Y, Chen H-Y, Jorba J, et al. Intratypic recombination among lineages of type 1 vaccine-derived poliovirus emerging during chronic infection of an immunodeficient patient. J Virol 2005;79:12623-12634.

26. Whitton JL, Cornell CT, Feuer R. Host and virus determinants of picornavirus pathogenesis and tropism. Nat Rev Microbiol 2005;3:765-776.

27. Signorini L, Barbi M, Matteelli A, et al. Prevalence of antipoliovirus type 1, 2 and 3 antibodies in unvaccinated Italian travellers. J Travel Med 2004;11:34-36. 
28. Racaniello VR. Picornaviridae: the viruses and their replication. In: Knipe DM, Howley PM, Griffin DE, et al., editors. Fields Virology. New York: Lippincott Williams \& Wilkins; 2001:685-772.

29. Girard S, Gosselin A-S, Pelletier I, Colbère-Garapin F, Couderc $\mathrm{T}$, Blondel B. Restriction of poliovirus RNA replication in persistently infected nerve cells. J Gen Virol 2002;83:1087-1093.

30. Julien J, Leparc-Goffart I, Lina B, et al. Postpolio syndrome: poliovirus persistence is involved in the pathogenesis. J Neurol 1999;246:472-476.

31. Wahid R, Cannon MJ, Chow M. Dendritic cells and macrophages are productively infected by poliovirus. J Virol 2005;79:401-409.

32. Klingel K, Stephan S, Sauter M, et al. Pathogenesis of murine enterovirus myocarditis: virus dissemination and immune cell targets. J Virol 1996;70:8888-8895.

33. Numazaki K, Goldman H, Bai XQ, Wong I, Wainberg MA. Effects of infection by HIV-1, cytomegalovirus, and human measles virus on cultured human thymic epithelial cells. Microbiol Immunol 1989;33:733-745.
34. Brilot F, Geenen V, Hober D, Stoddart CA. Coxsackievirus B4 infection of human fetal thymus cells. J Virol 2004; 78:9854-9861.

35. Vincent A, Leite MI, Farrugia ME, et al. Myasthenia gravis seronegative for acetylcholine receptor antibodies. Ann NY Acad Sci 2008;1132:84-92.

36. Pallansch M, Roos R. Enteroviruses: polioviruses, coxsackieviruses, echoviruses and newer enteroviruses. In: Knipe DM, Howley PM, Griffin DE, et al., editors. Fields Virology. Philadelphia: Wolters Kluwer; 2007: $840-884$.

37. Kew OM, Wringht PF, Agol VI, et al. Circulating vaccinederived polioviruses: current state of knowledge. Bull World Health Organ 2004;82:16-23.

38. Wringe A, Fine PEM, Sutter RW, Kew OM. Estimating the extent of vaccine-derived poliovirus infection. PLoS One 2008;3:1-11.

39. Osserman K, Genkis G. Studies in myasthenia gravis: review of a twenty-year experience in over 200 patients. Mt Sinai J Med 1971;38:497-537.

\section{Share Your Annual Meeting Plans. . .}

Join the conversation and start networking with your colleagues about your 2010 AAN Annual Meeting plans using your choice of the latest social media:

- Comment on or tweet about your most anticipated Annual Meeting program or event; tweet using \#AANAM

- Connect with colleagues and presenters ahead of the meeting

- Share your opinion on topics, programs, and presenters before the meeting begins

- Receive the latest Annual Meeting updates, news, and exclusive Annual Meeting discounts and specials_-for social media users only

- While at the meeting, learn about the new AAN.com communities, continue to post and tweet your comments, and monitor the latest social media posts from your fellow attendees via monitors in the convention center

Ewitker www.twitter.com/AANMember 


\section{Neurology}

\section{Detection of poliovirus-infected macrophages in thymus of patients with myasthenia gravis}

P. Cavalcante, M. Barberis, M. Cannone, et al.

Neurology 2010;74;1118-1126

DOI 10.1212/WNL.0b013e3181d7d884

\section{This information is current as of April 5, 2010}

Updated Information \& Services

Supplementary Material

References

Subspecialty Collections

Permissions \& Licensing

Reprints including high resolution figures, can be found at:

http://www.neurology.org/content/74/14/1118.full.html

Supplementary material can be found at:

http://www.neurology.org/content/suppl/2010/04/05/74.14.1118.DC1.h tml

This article cites 36 articles, 9 of which you can access for free at: http://www.neurology.org/content/74/14/1118.full.html\#\#ref-list-1

This article, along with others on similar topics, appears in the following collection(s):

Autoimmune diseases

http://www.neurology.org//cgi/collection/autoimmune_diseases

Myasthenia

http://www.neurology.org//cgi/collection/myasthenia

Viral infections

http://www.neurology.org//cgi/collection/viral_infections

Information about reproducing this article in parts (figures,tables) or in its entirety can be found online at:

http://www.neurology.org/misc/about.xhtml\#permissions

Information about ordering reprints can be found online:

http://www.neurology.org/misc/addir.xhtml\#reprintsus

Neurology ${ }^{\circledR}$ is the official journal of the American Academy of Neurology. Published continuously since 1951, it is now a weekly with 48 issues per year. Copyright . All rights reserved. Print ISSN: 0028-3878. Online ISSN: 1526-632X.

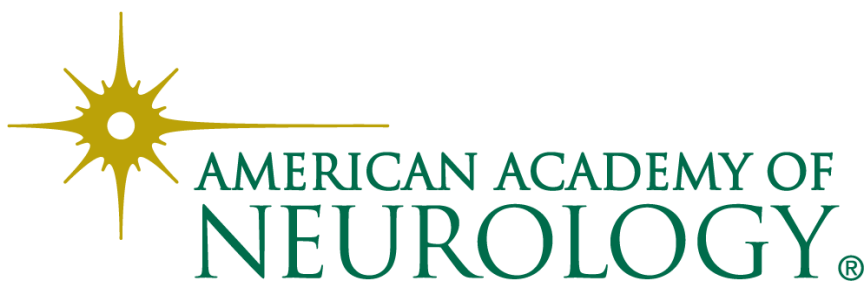

